\title{
Uridine supplementation with Mitocnol attenuates mitochondrial cardiomyopathy induced by zidovudine and zalcitabine K Balcarek ${ }^{1}$, D Lebrecht ${ }^{1}$, C Deveaud ${ }^{2}$, B Beauvoit ${ }^{2}$, J Bonnet ${ }^{2}$, J Kirschner ${ }^{3}$, N Venhoff*1 and UA Walker ${ }^{1}$
}

Address: ${ }^{1}$ University Hospital Freiburg/Dept. Rheumatology and Clinical Immunology, Freiburg, Germany, ${ }^{2}$ Institut de Biochimie et de Génétique Cellulaires, UMR 5095 CNRS-Université Victor Ségalen Bordeaux cedex, Bordeaux, France and ${ }^{3}$ University Hospital Freiburg/Department of Neuropediatrics and Muscle Disorders, Freiburg, Germany

* Corresponding author

from Ninth International Congress on Drug Therapy in HIV Infection

Glasgow, UK. 9-13 November 2008

Published: 10 November 2008

Journal of the International AIDS Society 2008, I I (SuppI I):PI47 doi:I0.II86/I758-2652-I I-SI-PI47

This abstract is available from: http://www.jiasociety.org/content/I I/SI/PI47

(c) 2008 Balcarek et al; licensee BioMed Central Ltd.

\begin{abstract}
Purpose of the study
Zidovudine is an antiretroviral nucleoside analogue reverse transcriptase inhibitor (NRTI). Long-term use of zidovudine is linked to a cardiomyopathy and various other tissue toxicities, which are associated with mitochondrial DNA (mtDNA) depletion. Because zidovudine inhibits thymidine kinases, the mechanism of mtDNA depletion may involve a restriction in the availability of phosphorylated pyrimidine nucleosides which are required as mtDNA and mtRNA building blocks. We investigated if the cardiomyopathy is a class effect of antiretroviral nucleoside analogues, and if the mitochondrial cardiotoxicity can be prevented with uridine as a pyrimidine nucleotide precursor.
\end{abstract}

\section{Methods}

$\mathrm{Balb} / \mathrm{c}$ mice were fed with zidovudine $(100 \mathrm{mg} / \mathrm{kg} / \mathrm{day})$ or zalcitabine $(13 \mathrm{mg} / \mathrm{kg} /$ day $)$. Mice were co-treated with or without Mitocnol (340 mg/kg/day), a dietary supplement with high uridine bioavailability. Cardiac muscle was examined after 9 weeks of treatment.

\section{Summary of results}

Zidovudine and zalcitabine both induced mitochondrial cardiotoxicity. Compared to untreated controls, the histopathological cardiomyopathy score was increased after treatment with zalcitabine $(312 \%, \mathrm{p}<0.001)$ and zidovudine $(540 \%, \mathrm{p}<0.001)$. Mitochondria were enlarged and their crystal architecture was disrupted. The organelles contained low mtDNA copy numbers (zidovudine $87.1 \%$, $\mathrm{p}=0.02$, zalzitabine $86.4 \%, \mathrm{p}=0.01$; compared to controls) and reduced cytochrome C-oxidase (COX) activity. The expression of the mtDNA-encoded COX I subunit, but not of nucleus encoded COX IV protein, was impaired. Uridine supplementation attenuated or normalized all pathology and had no intrinsic effects.

\section{Conclusion}

Both zidovudine and zalcitabine induced a mitochondrial cardiomyopathy, which is antagonized by uridine supplementation. The results provide proof of the importance of pyrimidine pools in the pathogenesis of zidovudine cardiomyopathy. As uridine supplementation is tolerated well by humans, this strategy should be investigated in clinical trials. 